\title{
Oral Mucosal Lesions in Children
}

\author{
Sura Ali Ahmed Fuoad ${ }^{1 *}$ and Shishir Ram Shatty ${ }^{2}$ \\ ${ }^{1}$ Associate Prof. \& Academic Associate Dean College of Dentistry/Gulf Medical University, UAE \\ ${ }^{2}$ Assistant Prof. College of Dentistry/Gulf Medical, UAE
}

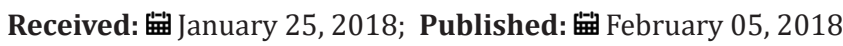

*Corresponding author: Sura Ali Ahmed Fuoad, Associate Professor in Academic Associate Dean College of Dentistry, Gulf Medical University, UAE

\begin{abstract}
Soft tissue lesions of the oral cavity are common in children, have various clinical presentations as colored lesions, mucosal ulceration or Nodular lesions and so. Some are a symptomatic and some are symptomatic or even disturb the daily activities of the child. When evaluating soft tissue lesions, it is important to distinguish between findings that are normal and those that are indicative a pathological condition, and normal anatomical variations. Most of adult oral soft tissue lesions may present in child oral cavity with predilection for some lesions. The literatures regarding oral mucosal lesions in children are relatively few. The most common oral disease, found was caries in priority and cancer therapy-related mucosal disorders.
\end{abstract}

Keywords: Oral lesions; Children; Soft tissue Nodules; Color changes

\section{Introduction}

As a result of usage of various diagnostic criteria, limited oral lesions included in the survey and absence of standardization, the prevalence of oral mucosal lesions in children is controversial. A cross-sectional retrospective study was done by Alessandra Majorana et al. [1] to evaluate the prevalence of oral mucosal lesions in 10,128 children aged 0-12 years in Italy .Oral mucosal lesions were detected in 2,918 (28.9\%) children. The most common lesions were oral candidiasis (28.4\%), followed by traumatic lesions $(17.8 \%)$, least common was erythema multiforme $(0.9 \%)$. children with systemic diseases were significantly had frequent oral mucosal lesions in comparison with healthy children. Traumatic oral soft tissue lesion is usually due to habits that cause injuries as food burns, lip and cheek biting, orthodontic devices, Sharp ends of wires in space maintainer or habit breaker, and any traumatic events. Andres Pinto et al in 2014, in his article (Pediatric Soft Tissue Oral Lesions) he divided the the lesions into several categorists according to lesions types as follows. Anatomic Variations in Gingiva, Frenum.

a) Developmental Lesions: Geographic tongue, Fissured tongue, Retro cuspid papillae ,Gingival overgrowth.

b) Mucosal Changes (COLOR): White Lesions, Lineaalba, Leukoedema, Pseudo membranous candidiasis, White sponge nevus. Red And/Or White Lesions: Petechiae, Purpura,
Ecchymosis, Erythematous Candidiasis. Angular Chelitis, Erythema Migrans (Benign Migratory Glossitis), Median Rhomboid Glossitis.

c) Brown-Black Lesions: Physiologic Pigmentation, Amalgam Tattoo/Graphite, Melanotic Nevus.

d) Soft Tissue Nodules: Inflammatory/reactive lesionsMucocele, Irritation fibroma, Peripheral ossifying fibroma, Pyogenic granuloma, Peripheral giant cell granuloma.

e) Benign Tumors: Hemangioma, Lymphatic malformations, Fibroma, Benign neoplasms

Squamous papilloma.

f) Cysts: Eruption cyst

g) Ulcerations: Traumatic ulcers,Aphthous ulcers.

h) Infections: Herpes simplex virus, Coxsackievirus, Herpangina, Hand, foot, mouth, Candida albicans, HIV infection [2].

In regards to Martha A [3] oral soft tissue lesions in children were classified according to their location as followings: Lesions Of The Gums that include, Eruption cyst or hematoma, Pigmentation, Retrocuspid papillae, Parulis ("gum boil"), Gingival overgrowth, 
Gingival recession, HIV gingivitis, Other lesions. Lesions of The Tongue include, Ankyloglossia ("tongue-tie"), Congenital lingual melanotic macules, Geographic tongue, Fissured tongue, Mucoceles, Other lesions. Lesions of the Lips involves, Herpes labialis, Angular cheilitis, Freckling, Abnormalities of the labial frena, Mucoceles and ranulas, Other lesions. Lesions of The Palate which are, Herpangina and Other lesions. Lesions of the Buccal Mucosa. Lesions That Occur at Multiple Sites as Benign tumors (Hemangiomas, Lymphangiomas)

Traumatic overgrowth (Irritation fibromas, Peripheral ossifying fibromas, Pyogenic granulomas, Peripheral giant cell granulomas, Ulcerations, Traumatic ulcers, Aphthous ulcers and Infections. Most of the oral lesions were diagnosed bases on clinical findings [4,5]. Some of the oral lesions are common as infection especially Herpes simples viral infection were found in $6.9 \%$ of children, regardless of the systemic health status, the primary attach is with sever oral and systemic clinical presentation usually [6]. In addition, acute pseudo membranous candidias is more likely to occur in children with systemic diseases, owing to local and systemic predisposing factors (immune-deficiencies, diabetes, endocrine disturbances, antibiotic therapies, corticosteroids therapies, malignancy, asthma, xerostomia and poor oral hygiene). Angular Chelitis which is chronic atrophic erythematous kind of fungal infection lesion at commissures $[7,8]$. Traumatic lesions as traumatic ulcers are mostly located in the tongue as it is the most motile organ in the oral cavity. Mucocelesmay occur any were in the oral mucosa on lips, buccal mucosa, tongue and palate .In children were commonly located on the lower lip [9]. HIstopathologic examination of the mucoceles revealed that almost all of them were of the extravasation type [10].

Localized reactive hyperplastic lesions such as, peripheral giant cell granuloma, focal fibrous hyperplasia, peripheral ossifying fibroma and pyogenic granuloma, all are result from chronic low grade irritation .Although it is of commonly observed in the second decade of life but it can occur in childhood the gingiva frequently affected site with a higher maxillary prevalence. Most of these lesions were symptomatic, nodular with bleeding with low recurrence rate [11]. Others rare lesions as in gingival fibromatosis is a rare, slowly-growing fibrous genetic and clinical heterogeneity, it could be drug induced or as a part of a syndrome. When gingival fibromatosis is a clinical manifestation of a syndrome is usually associated with generalized hypertrichosis, mental retardation, or epilepsy for such oral lesion with any systemic relation should be taken in consideration for the patient treatment planning and management [12]. Absence of the inferior labial and lingual frenulum was found to be associated with Ehlers-Danlos syndrome, the classical and hypermobility types [13]. On the other hand Ankyloglossiain which short, tight, lingual frenulum that cause impaired tongue function due to limitation in its movement. It is a congenital uncommon oral anomaly [14]. The oral cavity congenital malformations could involve any part of oral cavity, lips, floor of mouth, jaws, the hard palate, tongue and floor of mouth, as single or as more than single defect [15]. Few reports found regarding fissured tongue, Benign Migratory Glossitis (geographic tongue) in children. A transientharmless benign oral condition with low prevalence in paediatric population and of uncertain aetiology. The condition could besymptomatic in infected or asymptomatic [16].

Pigmented lesions as white lesion may present in children as in adults Linea alba, Leukoedema, White sponge nevus in which all are asymptomatic [17] while red purpul lesions could be due to local or systemic reason resulting in Petechiae, Purpura, Ecchymosis. Median Rhomboid Glossitis, a symptomatic in most patients, however, in some cases it is painful especially on irritation, revealed that although Mustafa Goregen et al. [18] found a significant association between Candida and diabetes mellitus and Median Rhomboid Glossitis, and that some risk factor were encounter [19]. Melanotic nevi present as localized brown, blue, gray, black, or colorless maculeor papule. The color variation depending on the location or depth, quantity of the pigmentation, the superficial appear brown the deeper looks blue or black that makes the diagnosis of the pigmented oral lesions challenging and crucial for the exclusion of potential risk of malignancies [20,21].

\section{References}

1. Alessandra Majorana, A Elena Bardellini, Pierangela Flocchini, Francesca Amadori, Giulio Conti, et al. (2010) Oral mucosal lesions in children from 0 to 12 years old: ten years' experience 110(1): p. e13-e18.

2. Andres Pinto, Christel M Haberland, Suher Baker (2014) Pediatric Soft Tissue Oral Lesions. Dent Clin N Am 58: 437-453.

3. Martha Ann Keels (2015) Soft tissue lesions of the oral cavity in children.

4. Masilana A, Khammissa RAG, Lemmer J, Feller L (2017) Physiological oral melanin pigmentation in a South African sample: A clinical study. J Investig Clin Dent 8(4).

5. Savoia F, Ricci L, Patrizi A, Gaddoni G (2015) Congenital melanotic macules of the tongue. A case report and brief review of the literature. Pediatr Dermatol 32(1): 109-112.

6. Tovaru S, Parlatescu I, Tovaru M, Cionca L (2009) Primary herpetic gingivostomatitis in children and adults. Quintessence Int 40(2): 11924.

7. Jabra Rizk MA, Torres SR, Rambob I, Meiller TF, Grossman LK, et al. (2007) Prevalence of oral Candida species in a North American pediatric population. J Clin Pediatr Dent 31(4): 260-263.

8. Epstein JB, Gorsky M, Caldwell J (2002) Fluconazole mouthrinses for oral candidiasis in postirradiation, transplant, and other patients. Oral Surg, Oral Med, Oral Pathol, Oral Radiol Endod 93(6): 671-675.

9. Gonzalez Gravina H, Gonzalez de Moran E, Zambrano 0 (2007) Oral candidias is in children and adolescents with cancer. Identification of Candida spp. Med Oral Patol Oral Cir Bucal 12(6): E419-423.

10. Minguez Martinez I, Bonet Coloma C, Ata Ali Mahmud J, Carrillo Garcia C, Penarrocha Diago M, et al. (2010) Clinical characteristics, treatment, and evolution of 89 mucoceles in children. J Oral Maxillofac Surg 68(10): 2468-2471.

11. Wu CW, Kao YH, Chen CM, Hen Jen hsu, Chun Ming Chen, et al. (2011) Mucoceles of the oral cavity in pediatric patients. Kaohsiung J Med Sci 27(7): 276-279.

12. Gordon Nunez MA, de Vasconcelos Carvalho M, Benevenuto TG, Lopes MF, Galvao HC et al. (2010) Oral pyogenic granuloma: a retrospective analysis of 293 cases in a Brazilian population. J Oral MaxillofacSurg 68(9): 2185-2188. 
13. Poulopoulos A, Kittas D, Sarigelou A (2011) Current concepts on gingival fibromatosis related syndromes. J Investig Clin Dent 2(3): 156-161.

14. De Felice C, Toti P, Di Maggio G, Parrini S, Bagnoli F (2001) Absence of the inferior labial and lingual frenula in Ehlers-Danlossyndrome. Lancet 357(9267): 1500-1502.

15. Tanay V, Chaubal Mala, Baburaj Dixit (2011) Ankyloglossia and its management. J Indian Soc Periodontol 15(3): 270-272.

16. Mueller DT, Callanan VP (2007) Congenital malformations of the oral cavity. Clin North Am 40(1): 141-160.

17. Doddabasavaiah Basavapur Nandini, Shivanand Bagalad Bhavana, Byathnal Suryakanth Deepak, Ramakrishna Ashwin (2016) Paediatric Geographic Tongue: A Case Report, Review and Recent Updates. J ClinDiagn Res 10(2): ZE05-ZE09.
18. Gonzalez Gravina H, Gonzalez de Moran E, Zambrano O, Robietrs S, Mesa L et al. (2007) Oral candidiasis in children and adolescents with cancer. Identification of Candida spp. Med Oral Patol Oral Cir Bucal 12(6): E419423.

19. Vieira Andrade RG, Zuquim Guimaraes Fde F, Vieira Cda S, Freire ST, Fernandes AM, et al. (2011) Oral mucosa alterations in a socioeconomically deprived region: prevalence and associated factors. Braz Oral Res 25(5): 393-400.

20. Mustafa Goregen, Ozkan Miloglu, Mustafa Cemil Buyukkurt, Fatma Caglayan, Ayse Esin Aktasd (2011) Median Rhomboid Glossitis: A Clinical and Microbiological Study. Eur J Dent. Oct 5(4): 367-372.

21. Rogério 0 Gondak, Rogério da Silva Jorge, Jacks Jorge, Márcio A Lopes, Pablo A Vargas (2012) Oral pigmented lesions: Clinicopathologic features and review of the literature. Med Oral Patol Oral Cir Bucal 17(6): e919-e924.

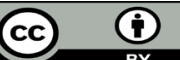

This work is licensed under Creative Commons Attribution 4.0 License

To Submit Your Article Click Here: Submit Article

DOI: $10.32474 /$ IPDOAJ.2018.01.000103

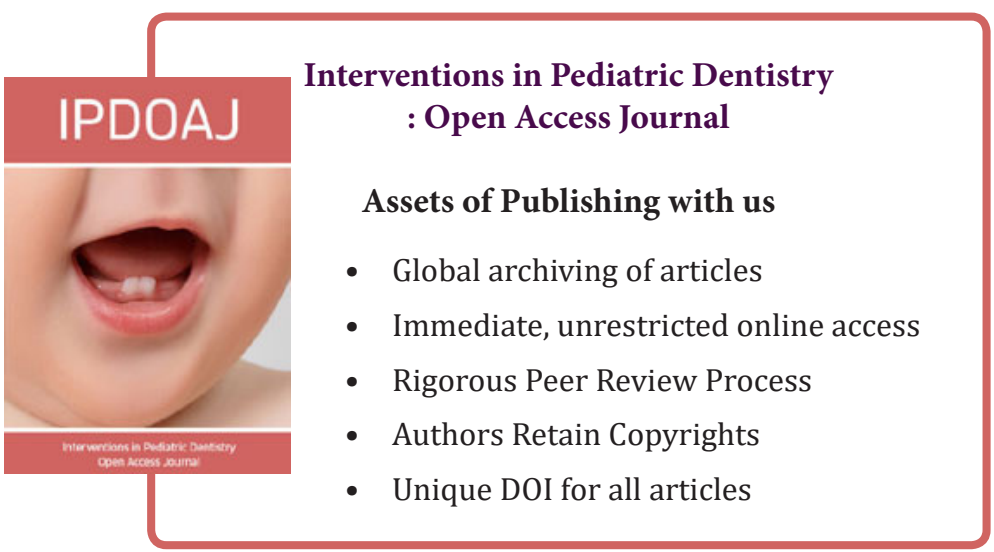

